\title{
Multi-objectives Optimal Scheduling in Smart Energy Hub System with Electrical and Thermal Responsive Loads
}

\author{
Heydar CHAMANDOUST ${ }^{1 *}$, Ghasem DERAKHSHAN ${ }^{2}$, Seyed MEHDI HAKIMI ${ }^{3}$, \\ Salah BAHRAMARA ${ }^{4}$ \\ ${ }^{1-3}$ Department of Electrical Engineering, Damavand Branch, Islamic Azad University, Tehran, Iran \\ ${ }^{4}$ Department of Electrical Engineering, Sanandaj Branch, Islamic Azad University, Sanandaj, Iran
}

\begin{abstract}
In this study, multi-objective optimal scheduling of smart energy Hub system (SEHS) in the day ahead is proposed. A SEHS is comprising of interconnected energy hybrid system infrastructures such as electrical, thermal, wind, solar, natural gas and other fuels to supply many types of electrical and thermal loads in a two-way communication platform. All objectives in this paper, are minimized and consist of 1) operation cost and emission polluting in generation side, 2) loss of energy supply probability (LESP) in demand side, and 3) deviation of electrical and thermal loads with the optimal level of electrical and thermal profile in the day ahead. The third objective to flatten electrical and thermal demand profile using Demand Side Management (DSM) by the optimal shifting of electrical and thermal shiftable loads (SLs) is proposed. Also, stochastic modelling of renewable energy sources (RESs) and electrical and thermal loads by Monte Carlo technique is modelled. Using GAMS optimization software, proposed approach by $\varepsilon$-constraint method for obtaining to non-dominated Pareto solutions of objectives is implemented. Moreover, by the decisionmaking method, the best solution of non-dominated Pareto solutions is selected. Finally, two case studies and sensitivity analysis in case studies for confirmation of the proposed approach are analysed.
\end{abstract}

Keywords - Decision-making method, Demand Side Management (DSM), Multi-objectives optimal scheduling, Smart energy Hub system (SEHS), \&-constraint method.

\begin{tabular}{|ll}
\hline Nomenclature & \\
Indices and sets & \\
b, B & Index/set of Boiler \\
d, D & Index/set of DG \\
ess, ESS & Index/set of ESS \\
EG & Index/set of Electrical grid \\
m, M & Index/set of CHP units \\
NGG & Index/set of Natural gas grid \\
pv, PV & Index/set of Photovoltaic (PV) \\
t, T & Index/set of time period \\
\hline
\end{tabular}

* Corresponding author.

E-mail address: H.Chamandoust.ac@gmail.com 


\begin{tabular}{|c|c|}
\hline TG & Index/set of Thermal grid \\
\hline tss, TSS & Index/set of TSS \\
\hline $\mathrm{s}, \mathrm{S}$ & Scenario indices \\
\hline $\mathrm{w}, \mathrm{W}$ & Index/set of Wind turbine (WT) \\
\hline \multicolumn{2}{|l|}{ Parameters } \\
\hline$a, b, c$ & Cost factors of DGUs, which by other fuels are supplied \\
\hline$d, e, f$ & Emission factors of DGUs, which by other fuels are supplied \\
\hline$c_{\mathrm{W}}$ & Scale index of WT \\
\hline $\mathrm{CO}_{2}, \mathrm{SO}_{2}, \mathrm{NO}_{\mathrm{x}}$ & $\begin{array}{l}\text { The greenhouse gases consisting of carbon dioxide }\left(\mathrm{CO}_{2}\right) \text {, sulphur dioxide } \\
\left(\mathrm{SO}_{2}\right) \text { and nitrogen oxides }\left(\mathrm{NO}_{\mathrm{x}}\right)\end{array}$ \\
\hline$D_{E}(s, t)$ & Electrical demand in Scenario s and at time t (MW) \\
\hline$D_{T}(s, t)$ & Thermal demand in Scenario s and at time t, MW \\
\hline$D_{G}(s, t)$ & Natural gas demand in Scenario $\mathrm{s}$ and at time $\mathrm{t}, \mathrm{m}^{3}$ \\
\hline $\begin{array}{l}D_{E}^{N R C}(s, t), \\
D_{E}^{R C}(s, t)\end{array}$ & $\begin{array}{l}\text { Electrical demand of non-responsive customers and responsive customers in } \\
\text { Scenario s and at time t, MW }\end{array}$ \\
\hline $\begin{array}{l}D_{T}^{N R C}(s, t), \\
D_{T}^{R C}(s, t)\end{array}$ & $\begin{array}{l}\text { Electrical demand of non-responsive customers and responsive customers in } \\
\text { Scenario s and at time t, MW }\end{array}$ \\
\hline$D_{E}^{O P}, D_{T}^{O P}$ & Optimal level of electrical and thermal demands, MW \\
\hline$C_{E S S}^{O P}, C_{T S S}^{O P}$ & Operating cost of ESS and TSS systems \\
\hline$P_{N, W T}$ & Total rated power of WT, MW \\
\hline$S_{P V}$ & Total area of $\mathrm{PV}, \mathrm{m}^{2}$ \\
\hline si & Solar irradiance, $\mathrm{kW} / \mathrm{m}^{2}$ \\
\hline$v$ & Wind speed, $\mathrm{m} / \mathrm{s}$ \\
\hline$V_{R}, V_{C i}, V_{C o}$ & Rated speed, cut-in speed, cut-off speed of WT, m/s \\
\hline$\alpha, \beta$ & Beta distribution function of PV \\
\hline$\xi_{E}, \xi_{T}$ & Participation level of RCs in electrical and thermal SLs shifting, \% \\
\hline$\eta_{P V}$ & Efficiency of PV, \% \\
\hline$\pi_{p}^{E G}$ & Electrical price in EG, $\$ / \mathrm{MW}$ \\
\hline$\pi_{p}^{T G}$ & Thermal price in TG, $\$ / M W$ \\
\hline$\pi_{p}^{g a s}$ & Natural gas price in NGG, $\$ / \mathrm{m}^{3}$ \\
\hline$\eta_{d i s}^{E S S}, \eta_{c h}^{E S S}$ & Efficiency of ESS in discharge and charge state, $\%$ \\
\hline$\eta_{d i s}^{T S S}, \eta_{c h}^{T S S}$ & Efficiency of TSS in discharge and charge state, $\%$ \\
\hline$\sigma_{d}, \mu_{d}$ & Standard deviation and mean for the demand values \\
\hline
\end{tabular}




\begin{tabular}{|c|c|}
\hline \multicolumn{2}{|l|}{ Decision variables } \\
\hline$C_{B}$ & Operation cost of boiler, $\$$ \\
\hline$C_{m}$ & Operation cost of CHP, \$ \\
\hline$C_{D G}$ & Operation cost of DG, $\$$ \\
\hline CESS & Operation cost of ESS, $\$$ \\
\hline CTSS & Operation cost of TSS, $\$$ \\
\hline$C_{E G}$ & Operation cost of EG, \$ \\
\hline$C_{T G}$ & Operation cost of TG, $\$$ \\
\hline$C_{N G G}$ & The cost of purchased natural gas, \$ \\
\hline$D_{E}^{R C}\left(s, t, t^{\prime}\right)$ & Demand shifted of electrical SLs by RC at time $t$ to $t^{\prime}$ in Scenario s, MW \\
\hline$D_{T}^{R C}\left(s, t, t^{\prime}\right)$ & Demand shifted of thermal SLs by RC at time $t$ to $t^{\prime}$ in Scenario s, MW \\
\hline$E_{B}$ & Emission pollution of boiler, $\mathrm{kg}$ \\
\hline$E_{m}$ & Emission pollution of $\mathrm{CHP}, \mathrm{kg}$ \\
\hline$E_{D G}$ & Emission pollution of DG, $\mathrm{kg}$ \\
\hline$E_{E G}$ & Emission pollution of EG, $\mathrm{kg}$ \\
\hline$E_{T G}$ & Emission pollution of $\mathrm{TG}, \mathrm{kg}$ \\
\hline$E_{E S S}, E_{T S S}$ & Energy of ESS and TSS, MW/h \\
\hline$T_{b}$ & Thermal generated by boiler, MW \\
\hline$T_{m}$ & Thermal generated by CHP, MW \\
\hline$T_{T G}$ & Thermal generated by TG, MW \\
\hline$P_{E S S}^{d i s}, P_{E S S}^{c h}$ & Electrical generated by ESS, MW \\
\hline$T_{T S S}^{d i s}, T_{T S S}^{c h}$ & Electrical generated by ESS, MW \\
\hline$P_{P V}$ & Electrical generated by PV, MW \\
\hline$P_{W T}$ & Electrical generated by WT, MW \\
\hline$P_{d}$ & Electrical generated by DG, MW \\
\hline$P_{m}$ & Electrical generated by $\mathrm{CHP}, \mathrm{kW}$ \\
\hline$P_{E G}$ & Electrical generated by EG, kW \\
\hline$G_{N G G}$ & Purchased natural gas by SEHS, $\mathrm{m}^{3}$ \\
\hline$\rho_{s}^{P V}, \rho_{s}^{W T}, \rho_{s}^{L}$ & Probability of PV, WT and demand in Scenario s \\
\hline$p_{\mathrm{s}}$ & Probability of Scenario s \\
\hline$\mu_{E E S-d i s}, \mu_{E E S-c h}$ & Binary variable of ESS in discharge and charge state \\
\hline$\mu_{T S S-d i s}, \mu_{T S S-c h}$ & Binary variable of TSS systems in discharge and charge state \\
\hline$\mu_{P S T}, \mu_{T S T}$ & Binary variable of electrical and thermal shortage \\
\hline
\end{tabular}




\section{INTRODUCTION}

The bilateral dependence between energies and social sustainability matters, such as economic, environmental and supply demand issues, have stimulated energy operators to evaluate many types of investigations on an energy scheduling issue [1]. Hence, utilization of energy hybrid system can have an impact on economic, environmental and reliability indices of system based on customer's behaviour in the energy consumption. However, one of the best advancements in the smart grids, establishing Smart Energy Hub System (SEHS) as multi-applications to supply the demand side [2], [3]. The SEHS, using bilateral communication link between customers and generation units, is able to provide optimal coordination between units and customers participating in load profile transformation. The changing in load profile has directed the effect on optimal energy dispatch, and can increase the flexibility of system such as minimization of the generation cost, emissions and improving reliability. The Demand Side Management (DSM) has encouraged customers to manage their consuming at peak time in order to flatten the demand curve, and can balance the generation pattern and demand in optimal operation. Actually, using DSM generation side can be managed by the demand side, and increasing energy operator's authority on optimal energy management of system [3], [4].

Also, DSM strategies can decrease generation costs in energy markets and coordinate the activities of the energy operator and customers to control the demand loads for the prevention of employing of extra units. With the advent of diverse loads such as electrical and thermal loads DSM strategies will be fundamental tool and potentially in the future energy management. The loads shaping by DSM have several strategies, such as load shifting, flexible load shape, strategic load building, valley filling, strategic conservation and peak clipping. In Fig. 1. DSM strategies are shown [3], [4]. The mentioned strategies can be utilized with attention to high energy pricing, improving load factor and reliability, reducing emissions etc.

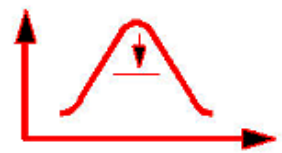

Peak Clipping

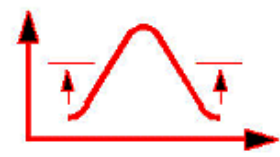

Valley Filling

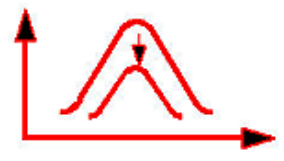

Conservation

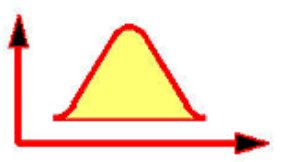

Flexible Load Shape
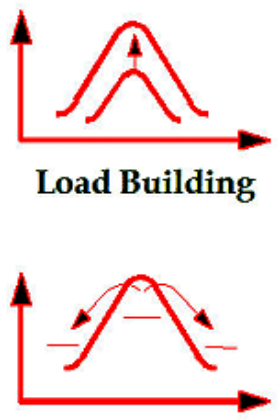

Load Shifting

Fig. 1. Demand Side Management strategies [3].

\subsection{Related Works}

In this subsection a number of previous works on energy hybrid systems perspective have been introduced as a literature review; many of the namely on scheduling, management, operation, planning, design of energy systems. In [5], short-term optimal scheduling of SEHS with consideration of the risk constraints, in order to minimise operation costs is studied. In [6], the 
optimal energy management of micro-scale energy hybrid as available resources, prices and demand for minimum energy cost, using iterative algorithm (IA) is proposed. In [7], scheduling of the SEHS based on multi-step standardized modelling, and DSM by multiplying the coupling matrix by graph theory (GT) are investigated. The optimal operation-based probabilistic optimization in the SEHS in order to maximize the SEHS profit is studied in [8]. In [9] scheduling strategy of SEHS under conditional value-at-risk ( $\mathrm{CVaR})$ with attention to DSM modelling for reducing generation costs is presented. The optimization of SEHS in Canadian buildings' archetypes for minimizing costs and emissions is analysed in [10]. The optimal energy management of energy hybrid system in order to increasing security of the demand supply by converting power to gas (P2G) technology is proposed in [11]. In [12] using online dictionary-learning approach (ODLA), probabilistic energy flow of energy hybrid systems for management of total energy costs in a SEHS is studied. In [13] optimization model of SEHS with consideration peak clipping of thermal and electrical curtailable loads (CLs) and reducing costs, customers' payments are investigated. The load flow analysis of electrical and thermal networks by Newton-Raphson iterative method (NRIM) in the energy hybrid systems in order to optimal design of SEHS is evaluated in [14]. In [15] optimal scheduling model of the SEHS under chance-constrained optimization of the renewable energy sources (RESs) uncertainties to minimize the costs and system investment is proposed. The multi quintessential schemes as cluster of demand side, sharing market, and aggregation in the energy hybrid systems under probabilistic load forecasts for maximum-utility perspective is studied in [16]. In [17] stochastic optimization of SEHS with attention to energy market prices and wind generation uncertainties for maximization of expected benefit is investigated. In [18] two-stage stochastic optimization framework in the SEHS with consideration risk-constrained scheduling is studied. The short-term scheduling framework of SEHS based on stochastic pricing in energy market by information gap decision theory (IGDT) is proposed in [19]. The design of sustainable SEHS in order to obtaining optimal size of resources with consideration RESs uncertainty using Benders decomposition algorithm (BDA) is studied in [20]. In [21] multi-period operation optimization of the energy hybrid systems by Particle Swarm Optimization (PSO) algorithm and interior-point approach (IPA) is analysed. The co-optimization modelling of the energy hybrid system as two-stage robust planning-operation and with attention to lifetime of the electrical storage systems (ESSs) is studied in [22]. In [23] a SEHS based micro energy grid in presence of the electrical responsive loads as optimal operation in day-ahead is analysed. In [24] cooperative trading framework of the SEHS as game theory approach (GTA), and with attention to stochastic characteristics of the RESs is proposed. In [25] optimal operation of the energy hybrid system in presence of the plug-in hybrid electric vehicles (PHEVs) uncertainty and risk-seeking constraints is investigated. The scheduling of the electrical SLs and PHEVs in the energy hybrid system in order to minimization of generation costs is studied in [26]. In [27] optimal scheduling and planning in the SEHS with consideration and assessment of operation cost, emission polluting and energy not supplied (ENS) in single objective is focused. The stochastic economic optimization under uncertainties of wind energy, electrical and thermal market prices is proposed in [28]. In [29] multi-energy scheduling of SEHS in the building users by alternating direction method of multipliers (ADMM) algorithm with consideration customer's satisfaction and maximizing social welfare is studied. The bi-level scheduling optimization of the energy hybrid system as power and gas system integration in order to minimizes the operational cost is investigated in [30]. In [31] optimal co-scheduling for P2G units and natural gas-fired distributed power generators (NGDG) in the power system is studied. The bi-objectives scheduling optimization of the SEHS as minimization of the operation cost and emission without DSM strategy is evaluated in [32]. The multi-objective hybrid location with consideration $M / M / C$ queuing framework and non-dominated sorting genetic algorithm 
(NSGA-II) is proposed in [33]. The economic and reliability indices of the SEHS as bi-objectives by weight sum method (WSM) is presented in [34]. In [35] using Genetic Algorithm (GA), operation cost and emission of the energy hybrid system are optimized. In [36] and [37] by fuzzy satisfying techniques (FST), the best solution of the non-dominated solutions in economic and environmental objectives of the SEHS is selected. The impact of electrical load shifting on operation cost and emission in the SEHS is proposed in [38] [39]. Using modified teaching-learning based optimization (MTLBO) algorithm, economic and environmental issues of the energy hybrid system is optimized in [40]. The optimization of the energy use, operation cost and emission in the energy hybrid system using GA and WSM is studied in [41]. A multi-objectives problem as energy efficiency, environmental and economic in order to optimization operation in the SEHS is evaluated in [42], [43]. The optimal design of the energy hybrid system, with attention to economic, environmental and installation area problems is analysed in [44].

\subsection{Contributions}

In this paper, a new multi-objective of the SEHS day ahead scheduling with minimization of operation cost is proposed, as well as emission polluting in generation side as first objective, minimizing loss of energy supply probability (LESP) in demand side as a second objective; and flatten demand profile curve of electrical and thermal with minimization of deviation between total demand and optimal level as a third objective. Using electrical and thermal shiftable loads (SLs) deviation in third objective with optimal level can be minimized. Moreover, non-dominated Pareto solutions of objectives by $\varepsilon$-constraint method is generated, and by Decision-making method the best solution is selected. The main contributions of this study are listed as follows:

- Tri-objectives scheduling of the SEHS with consideration economic, and environmental issues, reliability and demand optimal scheduling is proposed.

- Scheduling of electrical and thermal shiftable loads (SLs) as objective function in order to flatten electrical and thermal demand profile is modelled.

- The $\varepsilon$-constraint method as solution method to generating non-dominated Pareto solutions is employed.

- The best solution is selected by Decision-making method.

\subsection{Outline of the paper}

The remaining sections of this paper are classified as follows: in section 2 SEHS overview is explained. The Uncertainty modelling of PV, WT and demand is proposed in section 3 . The mathematical modelling of the proposed SEHS, including objective functions and constraints is presented in section 4 . The $\varepsilon$-constraint method as the solution method and decision-making method are explained in section 5. The numerical simulation, case studies and sensitivity analysis are carried out in section 7 . Finally, in section 8 , conclusion is provided.

\section{SEHS OVERVIEW}

The overview of the SEHS is expressed in this section. The SEHS has several main elements, including distributed generation units (DGUs), electrical grid (EG), thermal grid (TG), natural gas grid (NGG), other fuels and the customers. All elements are connected to a bilateral communication link with system operator in order to optimal coordination between generation side and demand side at the time of operation. For example, an operator can inform the demand 
side or customers based on pricing in the electricity, thermal and natural gas in energy markets to appropriate react of the customers with attention to current status. The elements of SEHS discussed in this paper are as follows.

\subsection{DGUs}

Generally, DGUs are divided into three types: 1) dispatchable units such as combined heat and power (CHP) units, diesel generator (DG) units and boiler units, which are supplied by fuels fossil and have operation cost and emission in energy generation, 2) non-dispatchable units consist of wind turbines (WT) and photovoltaics (PV) system that power output of them depend on weather status, and 3) storage systems comprising electrical storage systems (ESSs) and thermal storage systems (TSSs), which only have operation cost in charge and discharge cycles [9].

\subsection{EG, TG and NGG}

The purchased energy from EG, TG and NGG can have diverse price at the time of operation, which operator is able to coordinating demand side with attention to energy price.

\subsection{Customers}

In this paper, two types of customers in demand side are considered: 1) responsive customers (RCs) that based on the status of the system have suitable reaction, 2) non-responsive customers, which have no reaction in the system. Since in this paper load shifting of DSM strategies is used for demand scheduling, RCs can be shifted, as well as electrical and thermal SLs such as washing machines, electric vehicles (EVs), dryers, heating and cooling loads in the diverse time operation, in order to provide optimal state of the system [45]. SEHS overview is shown in Fig. 2.

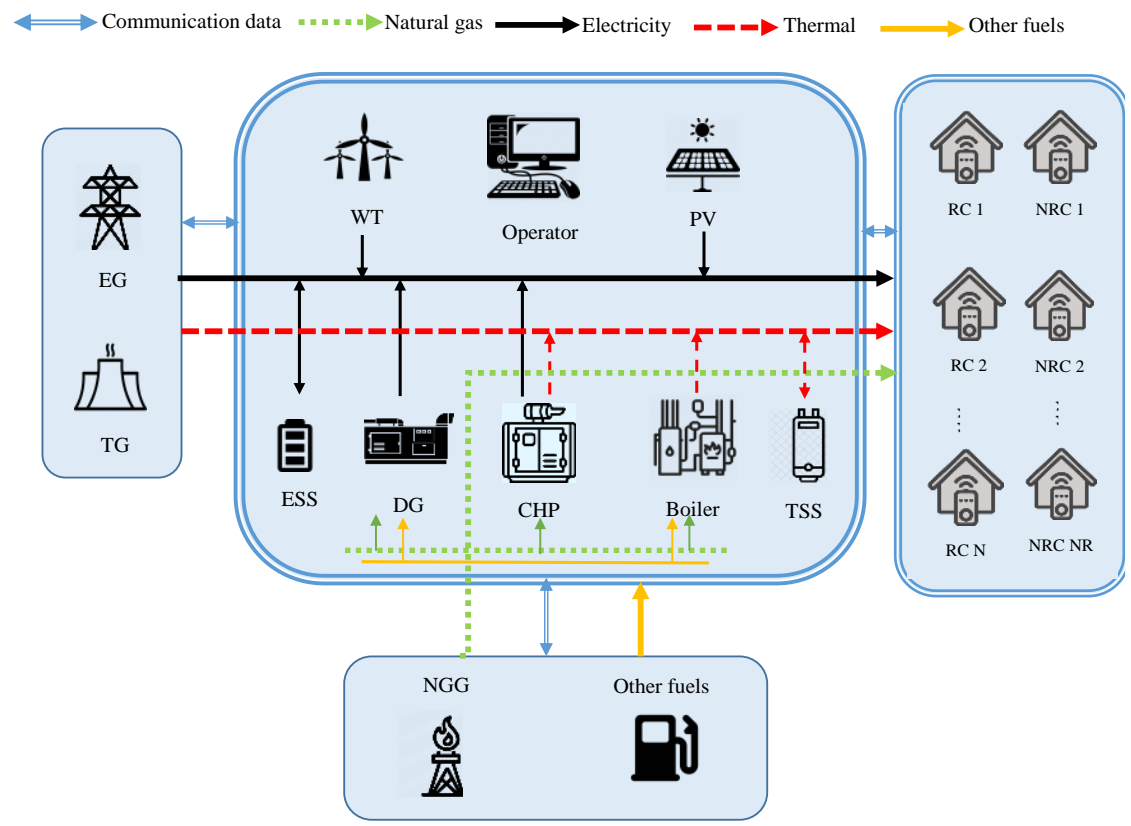

Fig. 2. Smart Energy Hub System overview. 


\section{UNCERTAINTY MODEL}

In this paper, forecast of RESs output, electrical and thermal demands as scenario-based probabilistic modelling by Monte Carlo technique is used. Also, probability in each state, using Probability Density Function (PDF) is obtained.

\subsection{PV model}

The energy output of the PV based on solar irradiance is measured, and using Beta PDF solar irradiance is modelled, which is expressed by (1) [46], [47].

$$
f^{P V}(s i)=\left\{\begin{array}{cc}
\frac{\Gamma(\alpha+\beta)}{\Gamma(\alpha) \Gamma(\beta)} s i^{\alpha-1}(1-s i)^{\beta-1} & 0 \leq s i \leq 1, \alpha \geq 0, \beta \geq 0 \\
0 & \text { otherwise }
\end{array}\right.
$$

and energy output of PV is as follow:

$$
P_{P V}(s i)=\eta_{P V} S_{P V} s i
$$

\subsection{WT model}

The wind speed forecast by Weibull PDF is modelled, which by is given by (3) [47].

$$
f^{W T}(v)=\left\{\begin{array}{cc}
\frac{k}{c_{w}}\left(\frac{v}{c_{w}}\right)^{k-1} \cdot e^{-\left(\frac{v}{c_{w}}\right)^{k}} & v \geq 0 \\
0 & \text { otherwise }
\end{array}\right.
$$

and energy output of WT is as follow:

$$
P_{W T}(v)=\left\{\begin{array}{ccc}
0 & \text { if } & v \leq V_{C i} \\
P_{N, W T}\left(\frac{v-V_{C i}}{V_{R}-V_{C i}}\right) & \text { if } & V_{C i} \leq v \leq V_{R} \\
P_{N, W T} & \text { if } & V_{R} \leq v \leq V_{C o} \\
0 & \text { if } & V_{C o} \leq v
\end{array}\right.
$$

\subsection{Demand model}

Using Gaussian PDF, uncertainty of electrical and thermal demands is expressed as follow [47]:

$$
L(d)=\frac{1}{\sqrt{2 \pi \sigma_{d}^{2}}} e^{-\frac{\left(d-\mu_{d}\right)^{2}}{2 \sigma_{d}^{2}}}
$$


Therefore, the probability of PV, WT and demands in each scenario can be integrated as follow [48]:

$$
\rho_{s}=\rho_{s}^{P V} \rho_{s}^{W T} \rho_{s}^{L}
$$

\section{OBJECTIVE FunCtions}

The main objectives in the SEHS are classified as tri-objectives and expressed as follow.

\subsection{First objective}

The minimization of operation cost, and emission polluting in generation side by first objective are modelled, as follows:

$$
\begin{aligned}
& \min f_{1}=\sum_{s=1}^{S} \rho_{s} \sum_{t=1}^{T}\left(\sum_{d=1}^{D} C_{D G}(s, t, d)+\sum_{b=1}^{B} C_{B}(s, t, b)+\sum_{m=1}^{M} C_{M}(s, t, m)+C_{E G}(s, t)+C_{T G}(s, t)+\right. \\
& \left.C_{N G G}(s, t)+\sum_{e s s=1}^{E S S} C_{E S S}(s, t, e s s)+\sum_{t s s=1}^{T S S} C_{T S S}(s, t, t s s)\right)+ \\
& \sum_{t=1}^{T}\left(\sum_{d=1}^{D} E_{D G}(t, d)+\sum_{b=1}^{B} E_{B}(t, b)+\sum_{m=1}^{M} E_{M}(t, m)+E_{E G}(t)+E_{T G}(t)\right)
\end{aligned}
$$

where

$$
\begin{gathered}
C_{D G}(s, t, d)=\left\{a P_{d}^{2}(s, t, d)+b P_{d}(s, t, d)+c\right\}+\left\{\pi_{p}^{g a s} \times P_{d}(s, t, d)\right\} \\
C_{B}(s, t, b)=\left\{a T_{b}^{2}(s, t, b)+b T_{b}(s, t, b)+c\right\}+\left\{\pi_{p}^{g a s} \times T_{B}(s, t, b)\right\} \\
C_{m}(s, t, m)=\left\{\pi_{p}^{g a s} \times\left(T_{m}(s, t, m)+P_{m}(s, t, m)\right)\right\} \\
C_{E G}(s, t)=\pi_{p}^{E G} P_{E G}(s, t) \\
C_{T G}(s, t)=\pi_{p}^{T G} T_{T G}(s, t) \\
C_{N G G}(s, t)=\pi_{p}^{g a s} G_{N G G}(s, t) \\
C_{E S S}(s, t, e s s)=\left\{C_{E S S}^{O P} \cdot P_{E S S}^{d i s}(s, t, e s s)\right\}+\left\{C_{E S S}^{O P} \cdot P_{E S S}^{c h}(s, t, e s s)\right\} \\
C_{T S S}(s, t, t s s)=\left\{C_{T S S}^{O P} \cdot T_{T S S}^{d i s}(s, t, t s s)\right\}+\left\{C_{T S S}^{O P} \cdot T_{T S S}^{c h}(s, t, t s s)\right\} \\
E_{D G}(t, d)=\left\{d P_{d}^{2}(t, d)+e P_{d}(t, d)+f\right\}+\left\{\left(\mathrm{CO}_{2}^{d}+\mathrm{SO}_{2}^{d}+\mathrm{NO}_{\mathrm{X}}^{d}\right) \cdot P_{d}(t, d)\right\} \\
E_{B}(t, b)=\left\{d T_{B}^{2}(t, b)+e T_{B}(t, b)+f\right\}+\left\{\left(\mathrm{CO}_{2}^{b}+\mathrm{SO}_{2}^{b}+\mathrm{NO}_{\mathrm{X}}^{b}\right) \cdot T_{b}(t, b)\right\}
\end{gathered}
$$




$$
\begin{aligned}
& E_{m}(t, m)=\left\{\left(\mathrm{CO}_{2}^{m}+\mathrm{SO}_{2}^{m}+\mathrm{NO}_{\mathrm{x}}^{m}\right) \cdot P_{m}(t, m)\right\} \\
& E_{E G}(t)=\left\{\left(\mathrm{CO}_{2}^{E G}+\mathrm{SO}_{2}^{E G}+\mathrm{NO}_{\mathrm{X}}^{E G}\right) \cdot P_{E G}(t)\right\} \\
& E_{T G}(t)=\left\{\left(\mathrm{CO}_{2}^{T G}+\mathrm{SO}_{2}^{T G}+\mathrm{NO}_{\mathrm{X}}^{T G}\right) \cdot T_{T G}(t)\right\}
\end{aligned}
$$

The operation cost of DG units, boiler units, CHP units using (8)-(10) can be calculated, respectively. The purchased electrical power, thermal power and natural gas from EG, TG and NGG by (11)-(13) are expressed, respectively. The operation cost of ESS and TSS in discharging and charging states using (14) and (15) are modelled, respectively. The emission equations of DG units, boiler units, CHP units, the EG and the TG by (16)-(20) are modelled, respectively. The first parts of (8) and (9), some of DG units and boilers units by other fuels are supplied, and second parts by natural gas are supplied. Also, first parts of (16) and (17) emission generation by DG units and boilers units using other fuels are modelled, and second part is modelled by natural gas.

\subsection{Second objective}

In second objective, LESP is minimized, which in this objective based on shortage of electrical and thermal power to supplied demand in each scenario and time is modelled.

$$
\min f_{2}=\sum_{s=1}^{S} \rho_{s}\left\{\left(\frac{\sum_{t=1}^{T} P_{S T}(s, t)}{\sum_{t=1}^{T} D_{E}(s, t)}\right)+\left(\frac{\sum_{t=1}^{T} T_{S T}(s, t)}{\sum_{t=1}^{T} D_{T}(s, t)}\right)\right\}
$$

Here, first and second part of (21) are shortage of electrical and thermal powers in each scenario and time, respectively.

\subsection{Third objective}

The flatten electrical and thermal demand profile using minimization of deviation rather than an optimal level by third objective is modelled. In this objective, shifting of electrical and thermal SLs by RCs can be done.

$$
\min f_{3}=\sum_{s=1}^{S} \rho_{s}\left\{\left(\sum_{t=1}^{T}\left|D_{E}(s, t)-D_{E}^{O P}\right|\right)+\left(\sum_{t=1}^{T}\left|D_{T}(s, t)-D_{T}^{O P}\right|\right)\right\}
$$

where

$$
\begin{gathered}
D_{E}(s, t)=D_{E}^{N R C}(s, t)+D_{E}^{R C}(s, t) \\
D_{T}(s, t)=D_{T}^{N R C}(s, t)+D_{T}^{R C}(s, t) \\
D_{E}^{R C}(s, t)=\sum_{t^{\prime}} D_{E}^{R C}\left(s, t^{\prime}, t\right)-\sum_{t^{\prime}} D_{E}^{R C}\left(s, t, t^{\prime}\right)
\end{gathered}
$$




$$
\begin{gathered}
D_{T}^{R C}(s, t)=\sum_{t^{\prime}} D_{T}^{R C}\left(s, t^{\prime}, t\right)-\sum_{t^{\prime}} D_{T}^{R C}\left(s, t, t^{\prime}\right) \\
0 \leq \sum_{t} D_{E}^{R C}\left(s, t, t^{\prime}\right) \leq \xi_{E} \cdot \sum_{t=1}^{T} D_{E}^{R C}(s, t) \\
0 \leq \sum_{t} D_{T}^{R C}\left(s, t, t^{\prime}\right) \leq \xi_{T} \cdot \sum_{t=1}^{T} D_{T}^{R C}(s, t) \\
D_{E}^{O P}=\frac{\sum_{t=1}^{T} D_{E}}{T} \\
D_{T}^{O P}=\frac{\sum_{t=1}^{T} D_{T}}{T}
\end{gathered}
$$

Using (23) and (24) new electrical and thermal demand profile are obtained, respectively. The shifting of electrical and thermal SLs by RCs from time t to $t^{\prime}$ in (25) and (26) are modelled, respectively. In (27) and (28) the participation level of RCs in electrical and thermal shifting are given, respectively. The optimal level of electrical and thermal demand profile in day ahead by (29) and (30) are modelled, respectively.

\section{Constraints}

Several constraints in SEHS are considered, which are as follow.

\subsection{Energy balance}

The energy balance constraint in order to covering of generation-side with demand-side in each scenario and time by (31)-(33) for electrical energy, thermal energy and natural gas are expressed, respectively.

$$
\begin{aligned}
& \sum_{d=1}^{D} P_{d}(s, t, d)+\sum_{m=1}^{M} P_{m}(s, t, m)+\sum_{e s s=1}^{E S S} P_{E S S}^{d i s}(s, t, e s s)+P_{E G}(s, t)+ \\
& \sum_{p v=1}^{P V} P_{P V}(s, t, p v)+\sum_{w=1}^{W} P_{w}(s, t, w)+P_{S T}(s, t)= \\
& D_{E}(s, t)+\sum_{e s s=1}^{E S S} P_{E S S}^{c h}(s, t, e s s)
\end{aligned}
$$




$$
\begin{aligned}
& \sum_{b=1}^{B} T_{b}(s, t, b)+\sum_{m=1}^{M} T_{m}(s, t, m)+\sum_{t s s=1}^{T S S} T_{T S S}^{d i s}(s, t, t s s)+T_{T G}(s, t)+T_{S T}(s, t)= \\
& T_{D}(s, t)+\sum_{t s s=1}^{T S S} T_{T S S}^{c h}(s, t, t s s) \\
& G_{N G G}(s, t)-\sum_{d=1}^{D} P_{d}(s, t, d)-\sum_{m=1}^{M} P_{m}(s, t, m)-\sum_{b=1}^{B} T_{b}(s, t, b)=D_{G}(t)
\end{aligned}
$$

\subsection{Energy limitations}

The constraints (34)-(41) indicate lower and upper energy limitation of DEGs, including DG units, boiler units, CHP units, ESSs and TSSs, respectively.

$$
\begin{gathered}
P_{d}^{\min } \leq P_{d}(s, t, d) \leq P_{d}^{\max } \\
T_{b}^{\min } \leq T_{b}(s, t, b) \leq T_{b}^{\max } \\
P_{m}^{\min } \leq P_{m}(s, t, m) \leq P_{m}^{\max } \\
T_{m}^{\min } \leq T_{m}(s, t, m) \leq T_{m}^{\max } \\
P_{d i s}(s, t, e s s) / \eta_{d i s}^{E S S} \leq P_{d i s}^{\max } \cdot \mu_{E S S-d i s}(s, t, e s s) \\
P_{c h}(s, t, e s s) \times \eta_{c h}^{E S S} \leq P_{c h}^{\max } \cdot \mu_{E S S-c h}(s, t, e s s) \\
T_{d i s}(s, t, t s s) / \eta_{d i s}^{T S S} \leq T_{d i s}^{\max } \cdot \mu_{T S S-d i s}(s, t, t s s) \\
T_{c h}(s, t, t s s) \times \eta_{c h}^{T S S} \leq T_{c h}^{\max } \cdot \mu_{T S S-c h}(s, t, t s s)
\end{gathered}
$$

Using (38)-(41) discharge and charge state of ESSs and TSS can be obtained, respectively. In addition, ESSs and TSSs are not able to discharge and charge at same time; these constraints are expressed by (42) and (43).

$$
\begin{gathered}
\mu_{E S S-d i s}(s, t, e s s)+\mu_{E S S-c h}(s, t, e s s) \leq 1 \\
\mu_{T S S-d i s}(s, t, t s s)+\mu_{T S S-c h}(s, t, t s s) \leq 1
\end{gathered}
$$

The constraints of electrical and thermal energy shortage to supplied demand are as follow:

$$
\begin{gathered}
0 \leq P_{S T}(s, t) \leq D_{E}(s, t) \cdot \mu_{P S T}(s, t) \\
0 \leq T_{S T}(s, t) \leq T_{E}(s, t) \cdot \mu_{T S T}(s, t)
\end{gathered}
$$

Here $\mu_{P S T}$ and $\mu_{T S T}$ are binary variable, and when they are equal to 1, energy shortage is occurred. 


\subsection{ESS and TSS technical constraints}

Using (46) and (47) technical constraints of ESSs and TSSs including energy dynamic limitation are expressed [49]:

$$
\begin{aligned}
& E_{E S S}^{\min } \leq E_{E S S}(s, t, e s s) \leq E_{E S S}^{\max } \\
& E_{T S S}^{\min } \leq E_{T S S}(s, t, t s s) \leq E_{T S S}^{\max }
\end{aligned}
$$

where

$$
\begin{aligned}
& E_{E S S}(s, t, e s s)=E_{E S S}(s, t-1, e s s)+\left[P_{E S S}^{d i s}(s, t, e s s) / \eta_{d i s}^{E S S}-P_{E S S}^{c h}(s, t, e s s) \cdot \eta_{c h}^{E S S}\right] \\
& E_{T S S}(s, t, t s s)=E_{T S S}(s, t-1, t s s)+\left[T_{T S S}^{d i s}(s, t, t s s) / \eta_{d i s}^{T S S}-T_{T S S}^{c h}(s, t, t s s) \cdot \eta_{c h}^{T S S}\right]
\end{aligned}
$$

\section{Solving the Problem}

In order to solve the proposed multi objective functions, $\varepsilon$-constraint method is used in this paper. The mathematical modelling of $\epsilon$-constraint method is used to introduce one of the objectives as main objective, and other objectives are divided into several segments; they are considered as inequality constraints. Then, the main objective is optimized in the inequality constraints and non-dominated Pareto solutions in each segment are obtained. In $\varepsilon$-constraint method, the optimization of the single objective is guaranteed with attention to other objectives that are assumed to inequality constraints. The step length in each segment is varied with consideration of different applications of the optimization modelling and the solving time. The modelling of the $\varepsilon$-constraint method is as follow [50]:

$$
\min _{x \in X} f_{j}(x)
$$

subject to

$$
f_{z}(x) \leq \varepsilon_{z} \quad z=1,2, \ldots, Z \quad z \neq j,
$$

where $x, j$ and $z$ are decision variable, main objective and other objectives in optimization process.

\subsection{Decision-making method}

Decision-making is a major tool for operators in order to achieve the optimal operation of systems. Since in this paper tri-objectives are optimized simultaneously, different non-dominated Pareto solutions in output of the problem are generated. Hence, the decision-making method is employed for selecting the best solution in the non-dominated solutions [51]. Fig. 3. has shown the selection of the best solution in bi-objective by decision-making method. The following steps should be performed in order to select the best solution:

1) Non-dominated Pareto solutions by (51) should be normalized;

2) Using (52), the minimum value of normalized non-dominated solutions is considered as ideal point $\left(\mathrm{P}_{\text {Ideal }}\right)$.

Equation (53) selects the minimum distance of $k^{\text {th }}$ solution from the ideal point as best solution. 


$$
\begin{gathered}
\Gamma_{z}^{k}=\frac{f_{z}^{\max }-f_{z}(k)}{f_{z}^{\max }-f_{z}^{\min }} \\
P_{\text {Ideal }}=\left\{\begin{array}{lll}
\min \Gamma_{1}^{1} \quad \min \Gamma_{2}^{2} & \ldots & \min \Gamma_{z}^{k}
\end{array}\right\} \\
\min \operatorname{Dis}(k)=\sqrt{\left[\Gamma_{1}^{1}-\min \Gamma_{1}^{1}\right]^{2}+\left[\Gamma_{2}^{1}-\min \Gamma_{2}^{2}\right]^{2}+\ldots+\left[\Gamma_{z}^{k}-\min \Gamma_{z}^{k}\right]^{2}},
\end{gathered}
$$

where $\Gamma_{z}{ }^{k}$ and $f(k)$ are normalized of $z^{\text {th }}$ objective in the $k^{\text {th }}$ solution and value of objective in $k^{\text {th }}$ solution, respectively.

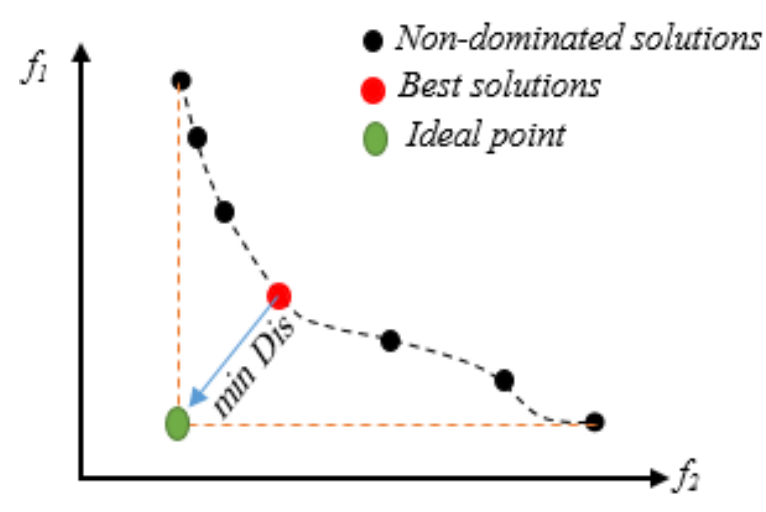

Fig. 3. Selecting the best solution by decision-making method.

\section{Case Studies and Numerical Simulation}

In this section, case studies and numerical simulation in order to validation of proposed approach in the SEHS scheduling at 24-ahead by mixed integer non-linear program (MINLP) and DICOPT solver in GAMS software are implemented. The DGUs in the proposed SEHS are comprised three DG units, two boiler units, two CHP units, five WT, five PV, one ESS and one TSS, and also SEHS is connected to EG, TG and NGG. Two case studies based on the presence of objectives in the SEHS are considered:

- Case I - Optimization of first and second objectives,

- Case II - Optimization of first, second and third objectives (flatten electrical and thermal demand profile).

Since in this paper wind speed, solar irradiance, and electrical and thermal demand have uncertain nature, 10 scenarios to forecast of WTs output, PVs output and demand have been generated by Monte Carlo technique. On the other hand, in order to prohibit of exhibiting and large number, in tables and figures in total scenarios, results accosted with scenario 6 have been analysed. In Fig. 4 wind speed and solar irradiance is depicted. It should be noted, all WTs and PVs have same data, and data of WTs and PVs is listed in Table 1. Fig. 5 has shown electrical, thermal and natural gas price. In Table 2, the ESS and TSS data are provided. The demand of electrical, thermal and natural gas is shown in Fig. 6. It is worth mentioning that some of dispatchable units, such as DG 1, DG 2 and Boiler 1 by other fuels are supplied, the economic and environmental data of which is listed in Table 3. The environmental data of DG 3, Boiler 2, 
CHPs 1 and 2, EG and TG based on greenhouse gases such as carbon dioxide $\left(\mathrm{CO}_{2}\right)$, sulphur dioxide $\left(\mathrm{SO}_{2}\right)$ and nitrogen oxides $\left(\mathrm{NO}_{\mathrm{x}}\right)$ is provided in Table 4 (DG 3, Boiler 2, CHP 1 and 2 by natural gas are supplied). In Table 5, energy limitations of dispatchable units are listed. The participation level of RCs for shifting electrical and thermal SLs are considered equal to $70 \%$ and $60 \%$, respectively.

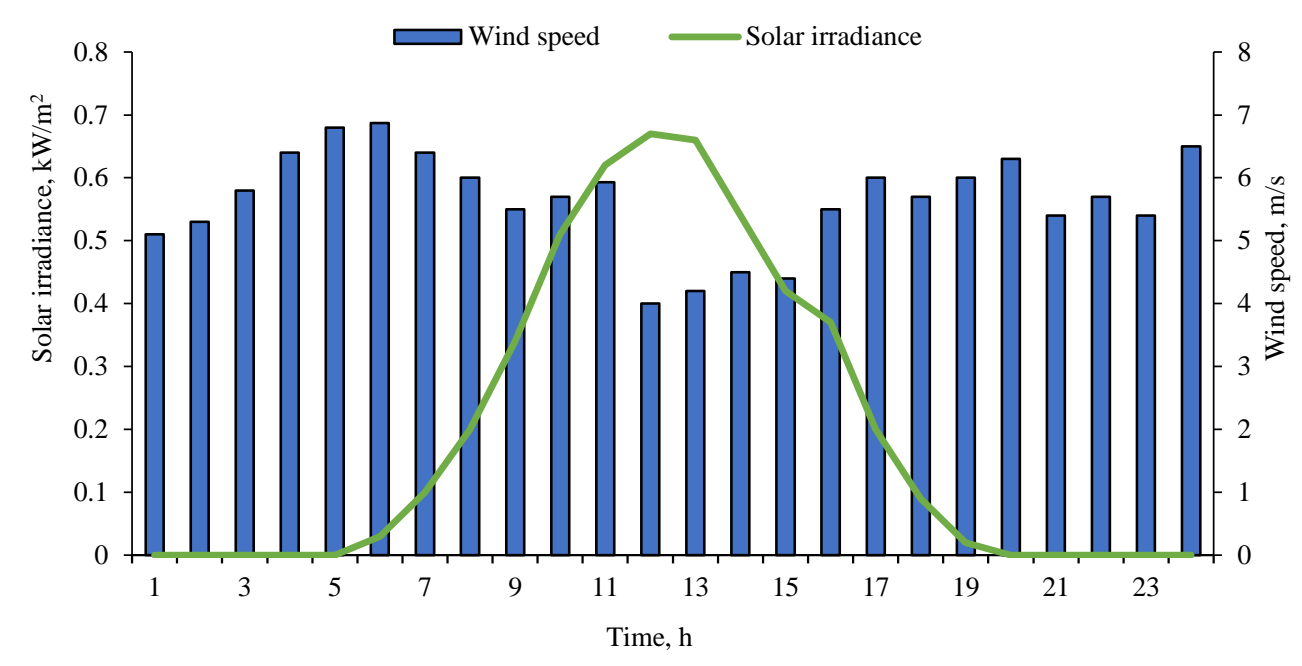

Fig. 4. Forecast of wind speed and solar irradiance in day ahead.

TABLE 1. WTS AND PVS DATA

\begin{tabular}{llll}
\hline \multicolumn{2}{c}{ PV } & \multicolumn{2}{c}{ WT } \\
\hline Parameters & Value & Parameters & Value \\
$N_{P V}$ & 5 & $N_{W T}$ & 5 \\
$S_{P V}$ & $45 \mathrm{~m}^{2}$ & $V_{C i}, V_{C o}$ & $3 \mathrm{~m} / \mathrm{s}, 20 \mathrm{~m} / \mathrm{s}$ \\
$\eta_{P V}$ & $25 \%$ & $V_{R}$ & $15 \mathrm{~m} / \mathrm{s}$ \\
$P_{N, P V}$ & $0.5 \mathrm{MW}$ & $P_{N, W T}$ & $1.2 \mathrm{MW}$ \\
\hline
\end{tabular}

TABLE 2. ESS AND TSS DATA

\begin{tabular}{llll}
\hline \multicolumn{2}{c}{ ESS } & \multicolumn{2}{c}{ TSS } \\
\hline Parameters & Value & Parameters & Value \\
\hline$N_{E S S}$ & 1 & $N_{T S S}$ & 1 \\
$P^{\max }{ }_{\text {dis }}$ & $1 \mathrm{MW}$ & $T^{\max }{ }_{d i s}$ & $0.5 \mathrm{MW}$ \\
$P^{\max }{ }_{c h}$ & $1 \mathrm{MW}$ & $T^{\max }{ }_{c h}$ & $0.5 \mathrm{MW}$ \\
$E^{\min }{ }_{E S S}$ & $10 \%$ & $E^{\min }{ }_{T S S}$ & $10 \%$ \\
$E^{\max }{ }_{E S S}$ & $100 \%$ & $E^{\max }{ }_{T S S}$ & $100 \%$ \\
$\eta^{E S S}$ & $90 \%$ & $\eta^{T S S}{ }_{c h}$ & $90 \%$ \\
$\eta^{E S S}{ }_{d i s}$ & $95 \%$ & $\eta^{T S S}{ }_{d i s}$ & $95 \%$ \\
$C^{O P}{ }_{E S S}$ & $140 \$$ & $C^{O P}{ }_{T S S}$ & $120 \$$ \\
\hline
\end{tabular}




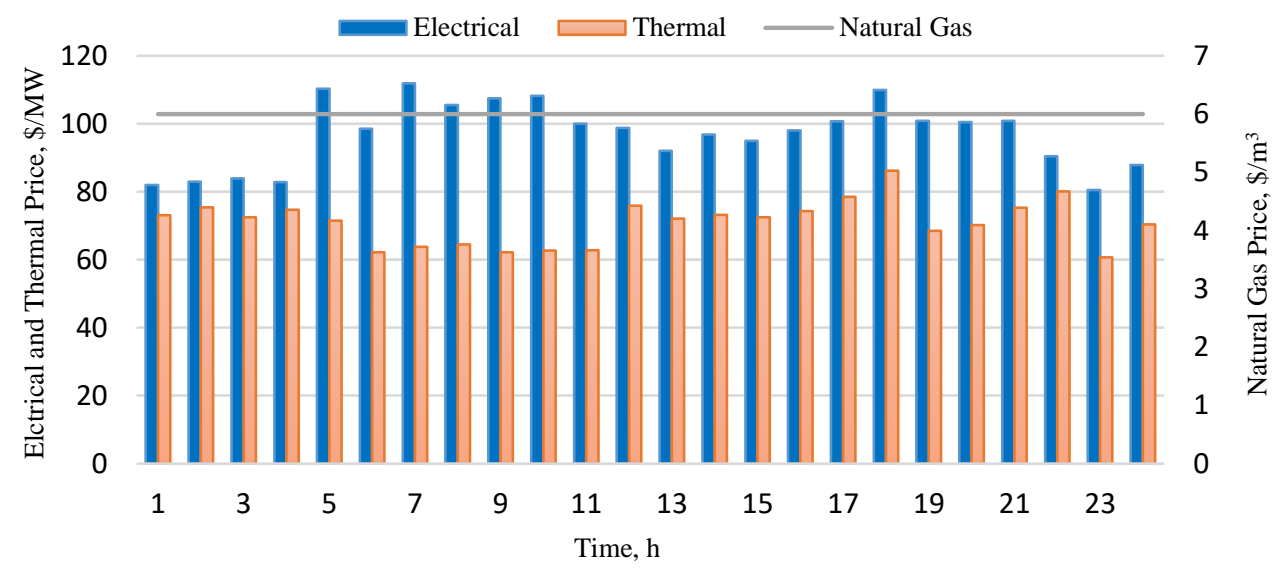

Fig. 5. Energy price in day ahead.

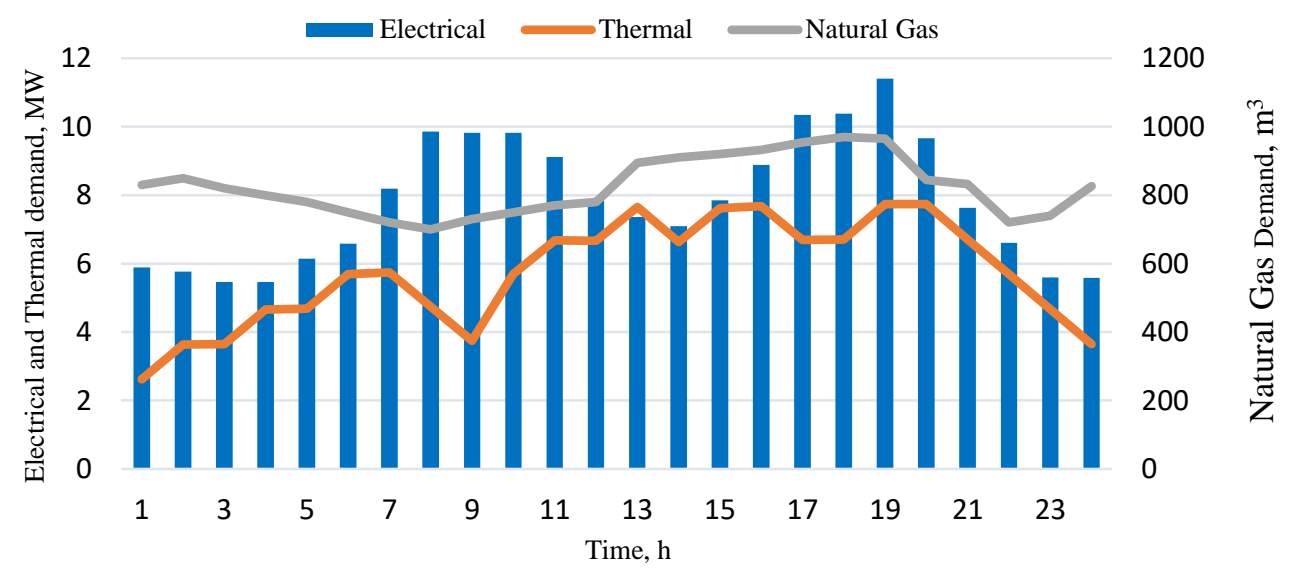

Fig. 6. Energy demand in SEHS.

TABLE 3. ECONOMIC AND ENVIRONMENTAL DATA OF DG 1, DG 2 AND BOILER 1

\begin{tabular}{lllllll}
\hline Parameters & $\boldsymbol{a}, \mathbf{\$} / \mathbf{M W}^{2}$ & $\boldsymbol{b}, \mathbf{\$} \mathbf{M W}$ & $\boldsymbol{c}, \mathbf{}$ & $\boldsymbol{d}, \mathbf{k g} / \mathbf{M W}^{2}$ & $\boldsymbol{e}, \mathbf{k g} / \mathbf{M W}$ & $\boldsymbol{f}, \mathbf{k g}$ \\
\hline Units & & & & & & \\
DG 1 & 25.5 & 140 & 102 & 21 & 154 & 108 \\
DG 2 & 25.5 & 141 & 102 & 21 & 154 & 108 \\
Boiler 1 & 20.5 & 95.7 & 100 & 21.5 & 90 & 105 \\
\hline
\end{tabular}


TABLE 4. ENVIRONMENTAL DATA OF UNITS

\begin{tabular}{llll}
\hline Emission type & $\mathbf{C O}_{2}, \mathbf{~ k g} / \mathbf{M W}$ & $\mathbf{S O}_{2}, \mathbf{k g} / \mathbf{M W}$ & $\mathbf{N O}_{\mathbf{x}}, \mathbf{k g} / \mathbf{M W}$ \\
\hline Units & & & \\
DG 3 & 475.5 & 3.42 & 1.94 \\
Boiler 2 & 490.3 & 3.54 & 1.26 \\
CHP 1 & 468.5 & 3.21 & 0.79 \\
CHP 2 & 469.2 & 3.15 & 0.15 \\
EG & 970.5 & 7.25 & 2.75 \\
TG & 951.4 & 7.31 & 1.69 \\
\hline
\end{tabular}

TABLE 5. ENERGY LIMITATIONS OF DISPATCHABLE UNITS

\begin{tabular}{lllll}
\hline Parameters & $\boldsymbol{P}^{\min }, \mathbf{M W}$ & $\boldsymbol{P}^{\max }, \mathbf{M W}$ & $\boldsymbol{T}^{\text {min }}, \mathbf{M W}$ & $\boldsymbol{T}^{\max }, \mathbf{M W}$ \\
\hline Units & & & & \\
DG 1 & 0 & 0.7 & - & - \\
DG 2 & 0 & 0.7 & - & - \\
DG 3 & 0 & 0.53 & - & - \\
Boiler 1 & - & - & 0 & 0.65 \\
Boiler 2 & - & - & 0 & 0.54 \\
CHP 1 & 0 & 0.55 & 0 & 0.51 \\
CHP 2 & 0 & 0.53 & 0 & 0.51 \\
\hline
\end{tabular}

\subsection{Results analysis}

In this subsection, results of numerical simulation in each case studies are discussed and case studies are compared with each other.

Case I) In Case I, first objective, including operation costs and emission polluting in scheduling of generation side, and also LESP as a second objective are minimized. Fig. 7(a) depicts generated non-dominated solutions using $\varepsilon$-constraint method. Using the decision-making method, the best solution of non-dominated solutions with minimum distance 0.7142 from ideal point is selected. The value of first and second objectives in the selected solution are equal to $286595.27^{\dagger} \mathrm{MW}$ and 0.011 MW, respectively. The operation costs of DG 1, DG 2, DG 3, Boiler 1, Boiler 2, CHP 1, CHP 2, ESS, TSS, purchased electrical from EG, purchased thermal from TG and purchased natural gas from NGG are equal to 3740.53 \$, 3742.46 \$, 64 \$, 2193.6 \$, 77.12 \$, 152.64 , 145.77 \$, 3360 \$, $1440 \$, 3126.45 \$, 5764.32 \$$ and 118225 \$, respectively. Also, emission generated by DGs, boilers, CHPs, EG and TG are $12816.33 \mathrm{~kg}, 13714.73 \mathrm{~kg}, 11731.62 \mathrm{~kg}$, $30331.33 \mathrm{~kg}$ and $75969.37 \mathrm{~kg}$, respectively. It is clear that maximum operation cost and emission polluting are related to natural gas purchased from NGG and TG, respectively. It can be said that high natural gas demand has direction effect on the operation cost. On the other hand, due to an uncertain nature of RESs and demand, energy shortage for meet demand, only occur in electrical power generation.

The generated electrical power of DGUs and EG to supply electrical demand is shown in Fig. 7(b). The shortage of electrical power at hours 17:00 to 19:00 is done, and total value of it at mentioned hours is equal to $2.1 \mathrm{MW}$. On the other hand, after RESs in meet electrical demand,

\footnotetext{
${ }^{\dagger}$ First objective function including cost, and emission, therefore we are not considering unit for it.
} 
EG has maximum participation covering electrical demand compared with dispatchable units, which power purchased from EG is $30.934 \mathrm{MW}$.

The thermal power generation of DGUs and TG in Fig. 7(c) is shown. As figure illustrates, maximum participation to meet thermal demand is related to $\mathrm{TG}$, which total generated thermal by TG is $79.101 \mathrm{MW}$.

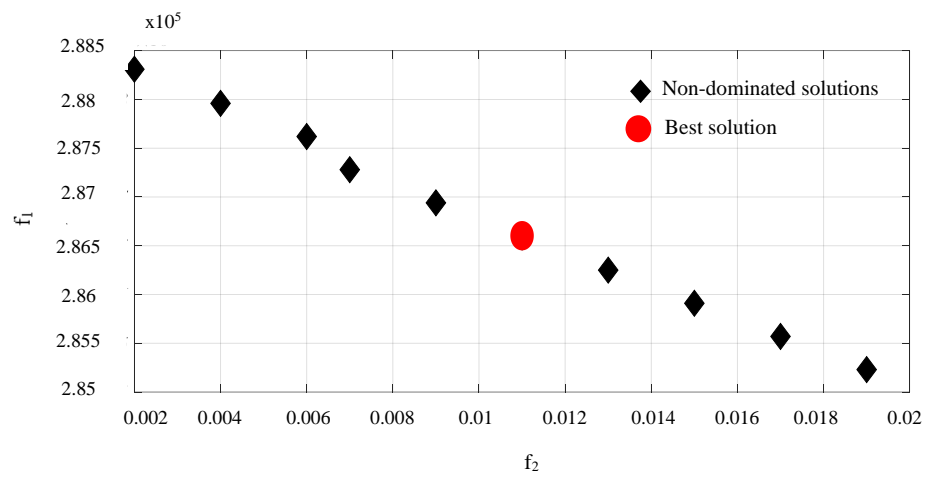

(a)

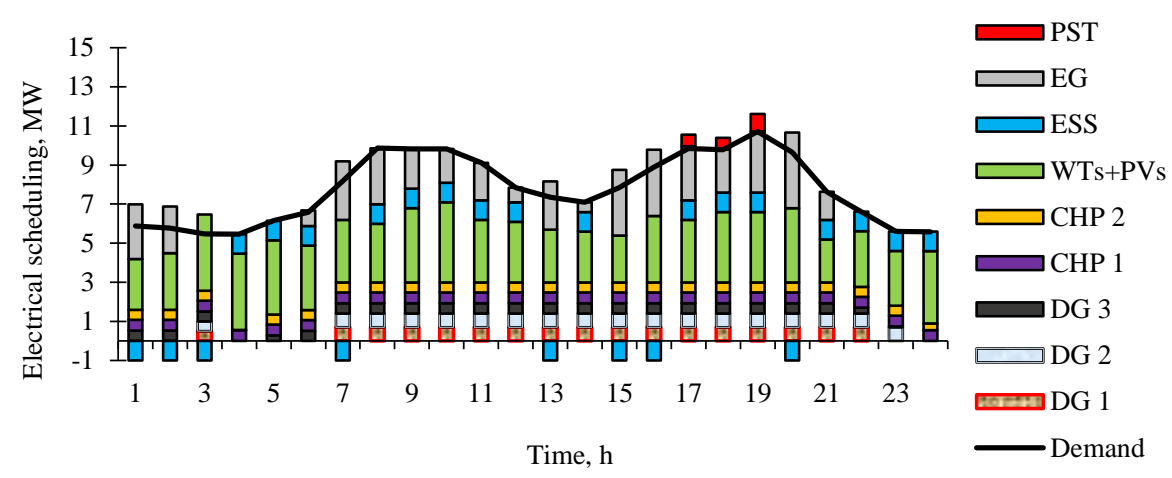

(b)

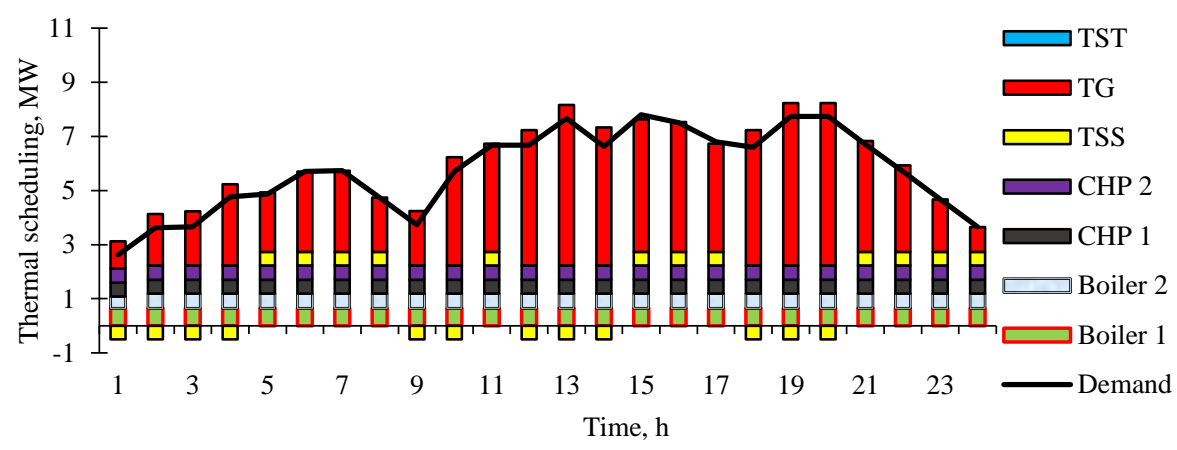

(c)

Fig. 7. (a) Selection of best solution in Non-dominated solutions in Case I, (b) Electrical power generated in Case I and (c) Thermal power generated in Case I. 
Case II) In this case, all objectives comprising scheduling of generation side, reliability and demand side as simultaneous in the SEHS are optimized. Fig. 8(a) illustrates ten generated non-dominated solutions of objectives by $\varepsilon$-constraint method, in which seventh solution with minimum distance 0.7731 from ideal point, using the decision-making method is determined. The operation cost and emission polluting in generation side in this case study are $140510.75 \$$ and $67124.98 \mathrm{~kg}$, respectively. The LESP, only in electrical energy is done, and total value of it, is equal to $0.005 \mathrm{MW}$. The deviation of third objective, in order to flatten electrical and thermal demand curve in selected solution, is $312.11 \mathrm{MW}$. The respective operation costs of boilers, TSS, EG and TG are reduced with quantity $5.16 \%, 0.97 \%, 34.26 \%$ and $79.9 \%$ than Case I, respectively. In addition, the reduction of emission polluting production in boilers, EG and TG, are $21.05 \%, 29.71 \%$ and $81.48 \%$ in comparison with Case I.

The schedulling of electrical demand and electrical power generated by DGUs and EG is depicted in Fig. 8(b). As shown, the electrical demand has more flattened curve than Case I, the total electrical power shortage is $0.95 \mathrm{MW}$ and only occurs at hour 19:00. The purchased electrical power from EG in this case $9.05 \%$ is less than Case I.

In Fig. 8(c), scheduling of thermal demand and generated thermal power by DGUs and TG is shown. The thermal generated by TG in this case is equal to $14.1 \mathrm{MW}$, which $82.17 \%$ is less than Case I. On the other hand, participation of Boilers 1 and 2 in order to meet thermal demand, $12.71 \%$ and $26.38 \%$ are reduced in comparison with Case I, respectively.

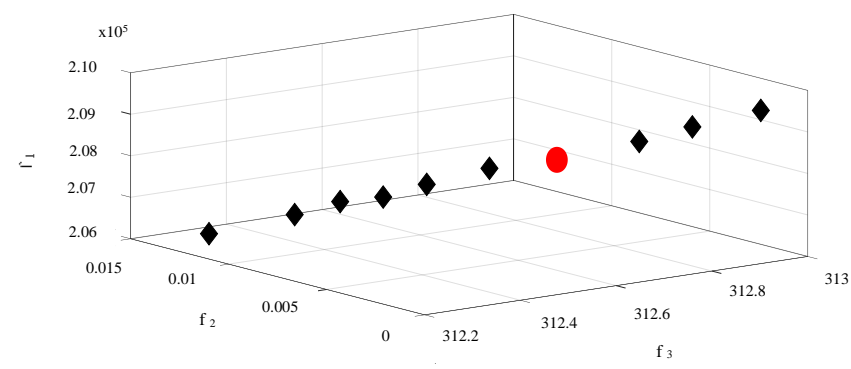

(a)

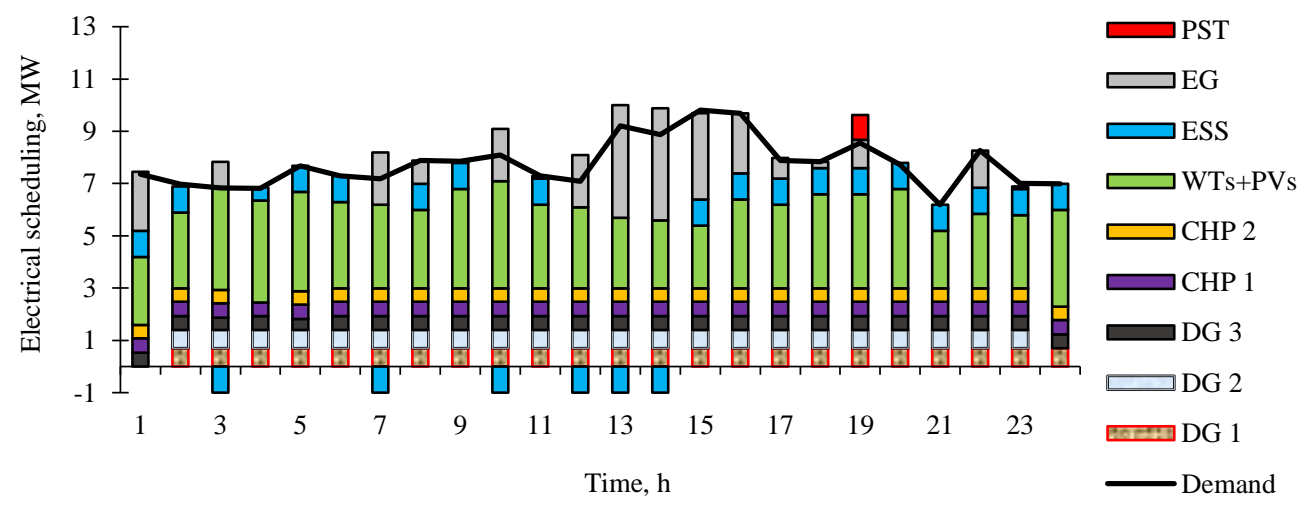

(b) 


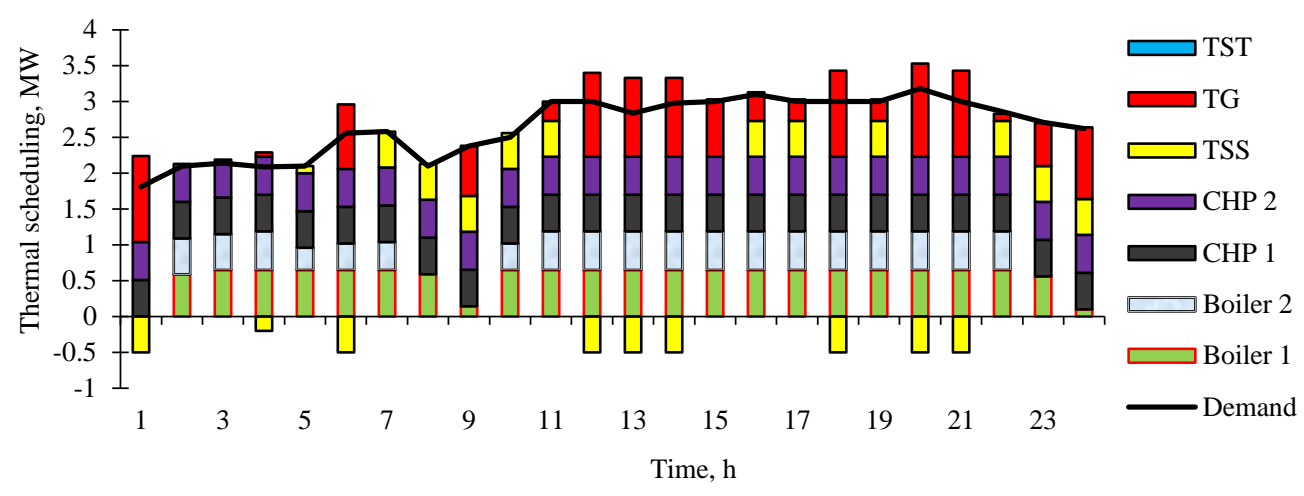

(c)

Fig. 8. (a) Selection of best solution in Non-dominated solutions in Case II, (b) Electrical power generated in Case II and (c) Thermal power generated in Case II.

\subsection{Sensitivity analysis in case studies}

In this subsection, sensitivity analysis in each case study is investigated. Hence, changing in parameters can have an impact on the objectives, and operator in SEHS must have appropriate decisions with attention to changes in these parameters. Therefore, case specifications such as sensitivity analysis based on increasing electrical, thermal and natural gas pricing are listed in Table 6. In the meantime, in Case II, participation level in shifting of electrical and thermal SLs by RCs, $25 \%$ and $20 \%$ are increased, respectively.

TABLE 6. SENSITIVITY ANALYSIS IN EACH CASE STUDY

\begin{tabular}{llllll}
\hline & Case I & \multicolumn{5}{l}{ Case II } \\
\hline $\begin{array}{l}\text { Case Specifications } \\
\text { Base Case }\end{array}$ & $f_{1}$ & $f_{2}$ & $f_{1}$ & $f_{2}$ & $f_{3}$ \\
$\begin{array}{l}\mathbf{5 0} \% \text { increasing } \\
\text { electrical price }\end{array}$ & 286595.27 & 0.011 & 207635.73 & 0.005 & 312.11 \\
$\begin{array}{l}\mathbf{5 0} \% \text { increasing } \\
\text { thermal price }\end{array}$ & 290311.57 & 0.011 & 207553.11 & 0.003 & 312.25 \\
$\begin{array}{l}\mathbf{1 0 0} \% \text { increasing gas } \\
\text { price }\end{array}$ & 406230.79 & 0.011 & 207501.01 & 0.003 & 312.47 \\
\hline
\end{tabular}

It is clear that the first objective in Case I, $0.66 \%, 1.27 \%$ and $29.45 \%$ is increased, in $50 \%$ increasing electrical price, $50 \%$ increasing thermal price and $100 \%$ increasing gas price in comparison with base case, respectively. On the other hand, Case II has optimal value in its objectives than Case I. 


\section{Conclusion}

In this study, economic, environmental and reliability scheduling, as well as demand performance appraisal with DSM strategy of a SEHS in day ahead have been analysed. The multi-objectives are minimized and classified as 1) operating cost and emission polluting, 2) LESP; and 3) deviation of electrical and thermal SLs with optimal level in day ahead. The third objective in order to flatten electrical and thermal demand curve with participation of RCs and by load shifting of DSM is modelled. Hence, to solving objectives, using the $\varepsilon$-constraint method, non-dominated solutions are generated and the best solution by decision-making method is selected. Two case studies are taken into account in order to perform a validation of the proposed modelling and approach in numerical simulation, the results of which are demonstrated as follow:

Case I. First and second objectives are optimized, which means operation cost, emission and LESP in selected solution are equal to $142031.89 \$, 144563.38 \mathrm{~kg}$ and $0.011 \mathrm{MW}$, respectively.

Case II. First and second objectives beside third objective is optimized, and $1.07 \%$ of operation costs, $53.56 \%$ of emission and $54.54 \%$ of LESP are decreased in comparison with Case I, respectively.

Also, sensitivity analysis is studied in Cases I and II, in which Case II with attention to changing parameter such as energies price has more optimal level than Case I.

\section{REFERENCES}

[1] Chamandoust H., Hashemi A., Derakshan G., Abdi B. Optimal hybrid system design based on renewable energy resources. Presented at IEEE Smart Grid Conference (SGC), 2017. https://doi.org/10.1109/SGC.2017.8308878

[2] Chamandoust H., Hashemi A., Derakshan G., Hakimi M. Scheduling of Smart Micro Grid Considering Reserve and Demand Side Management. Presented at IEEE Smart Grid Conference (SGC), 2018. https://doi.org/10.1109/SGC.2018.8777926

[3] Gelazanskas L., Gamage K. A. Demand side management in smart grid: A review and proposals for future direction. Sustainable Cities and Society 2014:11:22-30. https://doi.org/10.1016/j.scs.2013.11.001

[4] Blumberga A., Timma L., Blumberga D. System Dynamic Model for the Accumulation of Renewable Electricity using Power-to-Gas and Power-to-Liquid Concepts. Environmental and Climate Technologies 2016:16:54-68. https://doi.org/10.1515/rtuect-2015-0012

[5] Rold Blay C., Escrivá-Escrivá G., Roldán-Porta C., Álvarez-Belet C. An optimisation algorithm for distributed energy resources management in micro-scale energy hubs. Energy 2017:132:126-135. https://doi.org/10.1016/j.energy.2017.05.038

[6] Liu T., Zhang D., Wang S., Wu T. Standardized modelling and economic optimization of multi-carrier energy systems considering energy storage and demand response. Energy Conversion and Management 2019:182:126-142. https://doi.org/10.1016/j.enconman.2018.12.073

[7] Rakipour D., Barati H. Probabilistic optimization in operation of energy hub with participation of renewable energy resources and demand response. Energy 2019:173:384-399. https://doi.org/10.1016/j.energy.2019.02.021

[8] Jadidbonab M., Babaei E., Mohammadi-Ivatloo B. CVaR-constrained Scheduling Strategy for Smart Multi Carrier Energy Hub Considering Demand Response and Compressed Air Energy Storage. Energy 2019:174:1238-1250. https://doi.org/10.1016/j.energy.2019.02.048

[9] Ghorab M. Energy hubs optimization for smart energy network system to minimize economic and environmental impact at Canadian community. Applied Thermal Engineering 2019:151:214-230. https://doi.org/10.1016/j.applthermaleng.2019.01.107

[10] Gholizadeh N., Vahid-Pakdel M. J., Mohammadi-ivatloo B. Enhancement of demand supply's security using power to gas technology in networked energy hubs. Electrical Power and Energy Systems 2019:109:83-94. https://doi.org/10.1016/j.ijepes.2019.01.047

[11] Zhang N., Cheng J., Wang Y. Probabilistic Optimal Energy Flow of District Multi-energy Systems: An MPLP-based Online Dictionary-Learning Approach. IEEE Transactions on Industrial Informatics. Accepted for publishing.

[12] Aghamohamadi M., Samad M., Rahmat I. Energy Generation Cost in Multi-energy Systems; an Application to a Nonmerchant Energy Hub in Supplying Price Responsive Loads. Energy 2018:161:878-891. https://doi.org/10.1016/j.energy.2018.07.144 
[13] Ayele G. T., Haurant P., Laumert B., Lacarrière B. An extended energy hub approach for load flow analysis of highly coupled district energy networks: Illustration with electricity and heating. Applied Energy 2018:212:850-867. https://doi.org/10.1016/j.apenergy.2017.12.090

[14] Huo D., Gu C., Ma K., Wei W., Xiang Y., Le Blond S. Chance Constrained Optimization for Multi Energy Hub Systems in a Smart City. IEEE Transactions on Industrial Electronics 2019:66:1402-1412. https://doi.org/10.1109/TIE.2018.2863197

[15] Chen Y., Wei W., Liu F., Wu Q., Mei S. Analyzing and validating the economic efficiency of managing a cluster of energy hubs in multi-carrier energy systems. Applied Energy 2018:230:403-416. https://doi.org/10.1016/j.apenergy.2018.08.112

[16] Davatgaran V., Saniei M., Mortazavi S. S. Optimal bidding strategy for an energy hub in energy market. Energy 2018:148:482-493. https://doi.org/10.1016/j.energy.2018.01.174

[17] Dolatabadi A., Mohammadi-Ivatloo B. Stochastic Risk-constrained Scheduling of Smart Energy Hub in the Presence of Wind Power and Demand Response. Applied Thermal Engineering 2017:123:40-49. https://doi.org/10.1016/j.applthermaleng.2017.05.069

[18] Dolatabadi A., Jadidbonab M., Mahammadi-ivatloo B. Short-term Scheduling Strategy for Wind-based Energy Hub: A Hybrid Stochastic/IGDT Approach. IEEE Transactions on Sustainable Energy 2019:10:438-448. https://doi.org/10.1109/TSTE.2017.2788086

[19] Hemmati S., Ghaderi S. F., Ghazizadeh M. S. Sustainable Energy Hub Design under Uncertainty Using Benders Decomposition Method. Energy 2018:143:1029-1047. https://doi.org/10.1016/j.energy.2017.11.052

[20] Huo D., Le Blond S., Gu C., Wei W., Yu D. Optimal operation of interconnected energy hubs by using decomposed hybrid particle swarm and interior-point approach. Electrical Power and Energy Systems 2018:95:36-46. https://doi.org/10.1016/j.ijepes.2017.08.004

[21] Chen C., Sun H., Shen X., Guo Y., Guo Q., Xia T. Two-stage robust planning-operation co-optimization of energy hub considering precise energy storage economic model. Applied Energy 2019:252. In press. https://doi.org/10.1016/j.apenergy.2019.113372

[22] Ma T., Wu J., Hao L. Energy flow modeling and optimal operation analysis of the micro energy grid based on energy hub. Energy Conversion and Management 2017:133:292-306. https://doi.org/10.1016/j.enconman.2016.12.011

[23] Li Ma et al. Real-time Rolling Horizon Energy Management or the Energy-Hub-Coordinated Prosumer Community from a Cooperative Perspective. IEEE Transactions on Power Systems 2019:34:1227-1242. https://doi.org/10.1109/TPWRS.2018.2877236

[24] Moghaddas-Tafreshia S. M., Jafari M., Mohseni S., Kelly S. Optimal operation of an energy hub considering the uncertainty associated with the power consumption of plug-in hybrid electric vehicles using information gap decision theory. Electrical Power and Energy Systems 2019:112:92-108. https://doi.org/10.1016/j.ijepes.2019.04.040

[25] Salehimaleh M., Akbarimajd A., Valipour K., Dejamkhooy A. Generalized modeling and Optimal Management of Energy Hub based Electricity, Heat and Cooling Demands. Energy 2018:159:669-685 https://doi.org/10.1016/j.energy.2018.06.122

[26] Pazouki S., Haghifam M. A. Uncertainty modeling in optimal operation of energy hub in presence of wind, storage and demand response. Electrical Power and Energy Systems 2014:61:335-345. https://doi.org/10.1016/j.ijepes.2014.03.038

[27] Vahid-Pakdel M. J., Nojavan S., Mohammadi-ivatloo B., Zare K. Stochastic optimization of energy hub operation with consideration of thermal energy market and demand response. Energy Conversion and Management 2017:145:117128. https://doi.org/10.1016/j.enconman.2017.04.074

[28] Zhong W., Yang C., Xie K., Xie S., Zhang Y. ADMM-Based Distributed Auction Mechanism for Energy Hub Scheduling in Smart Buildings. IEEE Access 2018:6:45635-45645. https://doi.org/10.1109/ACCESS.2018.2865625

[29] Shu K., Ai X., Fang J., Yao W., Chen Z., He H., Wen J. Real-time subsidy based robust scheduling of the integrated power and gas system. Applied Energy 2019:236:1158-1167. https://doi.org/10.1016/j.apenergy.2018.12.054

[30] Sheykhloei B., Abedinzadeh T., Mohammadian L., Mohammadi-Ivatloo B. Optimal co-scheduling of distributed generation resources and natural gas network considering uncertainties. Journal of Energy Storage 2019:21:383-392. https://doi.org/10.1016/j.est.2018.11.018

[31] Nojavan S., Majidi M., Zare K. Optimal scheduling of heating and power hubs under economic and environment issues in the presence of peak load management. Energy Conversion and Management 2018:156:34-44. https://doi.org/10.1016/j.enconman.2017.11.007

[32] Khodemani-Yazdi M., Tavakkoli-Moghaddam R., Bashiri M., Rahimi Y. Solving a new bi-objective hierarchical hub location problem with an $M / M / C$ queuing framework. Engineering Applications of Artificial Intelligence 2019:78:5370. https://doi.org/10.1016/j.engappai.2018.10.004

[33] Amiri S., Honarvar M., Sadegheih A. Providing an Integrated Model for Planning and Scheduling Energy Hubs and Preventive Maintenance. Energy 2018:163:1093-1114. https://doi.org/10.1016/j.energy.2018.08.046

[34] Sani M. M., Noorpoor A., Shafie-Pour M. M. Optimal model development of energy hub to supply water, heating and electrical demands of a cement factory. Energy 2019:177:574-592. https://doi.org/10.1016/j.energy.2019.03.043 
[35] Maroufmashat A. et al. Modeling and optimization of a network of energy hubs to improve economic and emission considerations. Energy 2015:93:2546-2558. https://doi.org/10.1016/j.energy.2015.10.079

[36] Majidi M., Nojavan S., Zare K. A cost-emission framework for hub energy system under demand response program. Energy 2017:134:157-166. https://doi.org/10.1016/j.energy.2015.10.079

[37] Soudmand B. M., Esfetanaj N. N., Mehdipour S., Rezaeipour R. Heating hub and power hub models for optimal performance of an industrial consumer. Energy Conversion and Management 2017:150:425-432. https://doi.org/10.1016/j.enconman.2017.08.037

[38] Wei P., He F., Li L., Shi X., Simoes R. Multi-objective problem based operation and emission cots for heat and power hub model through peak load management in large scale users. Energy Conversion and Management 2018:171:411426. https://doi.org/10.1016/j.enconman.2018.05.025

[39] Shabanpour-Haghighi A., Seifi A. R. Multi-objective operation management of a multi-carrier energy system. Energy 2015:88:430-442. https://doi.org/10.1016/j.energy.2015.05.063

[40] Kampouropoulos K., Andrade F., Sala E., Espinosa A., Romeral L. Multiobjective Optimization of Multi-Carrier Energy System using a combination of ANFIS and Genetic Algorithms. IEEE Transactions on Smart Grid 2018:22762283. https://doi.org/10.1109/TSG.2016.2609740

[41] Zhao F., Zhang C., Sun B. Initiative Optimization Operation Strategy and Multi-objective Energy Management Method for Combined Cooling Heating and Power. IEEE/CAA Journal of Automatica Sinica 2016:(3):385-393. https://doi.org/10.1109/JAS.2016.7510079

[42] Eriksson E. L. V., Gray E. MacA. Optimization of renewable hybrid energy systems - A multi-objective approach. Renewable Energy 2019:133:971-999. https://doi.org/10.1016/j.renene.2018.10.053

[43] Jing R. et al. Comparative study of posteriori decision-making methods when designing building integrated energy systems with multi-objectives. Energy \& Buildings 2019:194:123-139. https://doi.org/10.1016/j.enbuild.2019.04.023

[44] Chamandoust H. et al. Tri-objective optimal scheduling of smart energy hub system with schedulable loads. Journal of Cleaner Production 2019:236:117584. https://doi.org/10.1016/j.jclepro.2019.07.059

[45] Bariss U., Bazbauers G., Blumberga A., Blumberga D. System Dynamics Modeling of Households' Electricity Consumption and Cost-Income Ratio: A Case Study of Latvia. Environmental and Climate Technologies 2017:20:3650. https://doi.org/10.1515/rtuect-2017-0009

[46] Chamandoust H. Economic Scheduling of Micro Grid Based on Energy Management and Demand Response. Electrical, Control and Communication Engineering 2018:14:100-107. https://doi.org/10.2478/ecce-2018-0012

[47] Kittipongvises S., Chavalparit O., Sutthirat C. Greenhouse Gases and Energy Intensity of Granite Rock Mining Operations in Thailand: A Case of Industrial Rock-Construction. Environmental and Climate Technologies 2016:18:64-75. https://doi.org/10.1515/rtuect-2016-0014

[48] Chamandoust H. et al. Multi-objective performance of smart hybrid energy system with Multi-optimal participation of customers in day-ahead energy market. Energy and Buildings 2020:216:109964. https://doi.org/10.1016/j.enbuild.2020.109964

[49] Mavrotas G. Effective implementation of the $\epsilon$-constraint method in Multi-Objective Mathematical Programming problems. Applied Mathematics and Computation 2009:213:455-465. https://doi.org/10.1016/j.amc.2009.03.037

[50] Chamandoust H. et al. Tri-objective scheduling of residential smart electrical distribution grids with optimal joint of responsive loads with renewable energy sources. Journal of Energy Storage 2020:27:101-112. https://doi.org/10.1016/j.est.2019.101112

[51] Saberi K. et al. Optimal performance of CCHP based microgrid considering environmental issue in the presence of real time demand response. Sustainable Cities and Society 2019:45:596-606. https://doi.org/10.1016/j.scs.2018.12.023

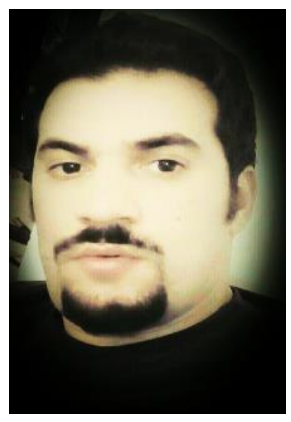

Heydar Chamandoust was born in Kermanshah, Iran, in 1990. He received M. sc. degrees in electrical engineering from the Islamic Azad University branch of Sanandaj, Kurdistan, Iran, in 2015. He is currently a Ph. D. student at the Islamic Azad University branch of Damavand, Tehran. His research interests include energy management, smart grids, and wide area monitoring.

E-mail: $\underline{\text { H.chamandoust.ac@gmail.com }}$

ORCID iD: https://orcid.org/0000-0001-7847-2444 


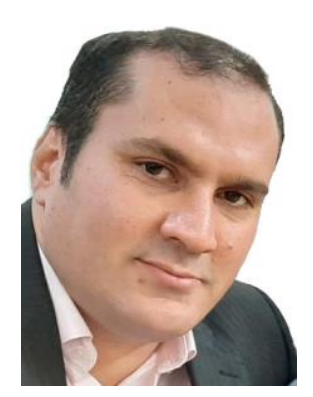

Ghasem Derakhshan received the B.Sc. and M.Sc. degrees in Electrical Engineering in 2006 and 2009, respectively. He received his $\mathrm{Ph}$. D. degree in Electrical Engineering from Iran University of Science and Technology, Tehran, Iran in 2016. Currently, he is an Assistant Professor in Technical Eng. Department of Islamic Azad University, Damavand Branch and Renewable Energy Research Center. His research interests are smart grid, power system planning, renewable energy and GIS.

E-mail: G.derakhshan.ac@ gmail.com

ORCID iD: https://orcid.org/0000-0002-7274-942X

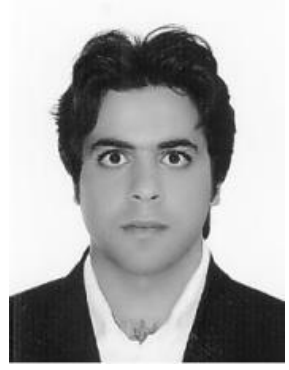

Seyed Mehdi Hakimi received the B.Sc. degree from the Shiraz University, Iran, in 2004, and the M.Sc. and Ph.D. degrees from the K. N. Toosi University of technology Tehran, Iran, in 2007 and 2014, all in electrical engineering. He is an Assistant Professor with the Damavand University, Damavand, Iran, from 2014 to now. His current research interests include smart grid, Renewable energy, Demand response and Internet of Thing (IoT).

E-mail: sm_hakimi83@yahoo.com

ORCID iD: https://orcid.org/0000-0002-9352-7869

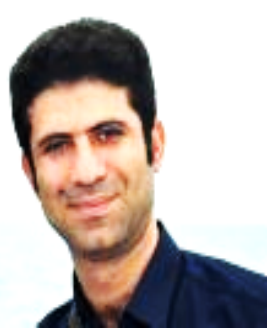

Salah Bahramara (M'16) received the M.Sc. degree in electrical engineering from Tehran University in 2012 and the Ph.D. degree in electrical engineering from Tarbiat Modares University in 2016. He is currently an Assistant Professor in electrical engineering with Islamic Azad University, Sanandaj Branch, Sanandaj, Iran. His research interests include active distribution networks, micro-grids, and bi-level optimization.

E-mail: S-bahramara@yahoo.com

ORCID iD: https://orcid.org/0000-0002-5123-0960 